\title{
1000 Versus 635 Days Approach for Prevention of Undernutrition in Children
}

\author{
Harivansh Chopra \\ National President Elect (2021-2022), Indian Association of Preventive \& Social Medicine \\ Former Professor \& Head, Department of Community Medicine, LLRM Medical College, Meerut
}

Since the pre-independence era, India is dealing with a variety of health problems that have been eliminated in developed nations. As we prepare to enter post covid era, a problem which we are dealing since ages is child promotion and child survival. India is a nuclear weapon-affiliated country now but it still has a long way to go as far as child malnutrition is concerned. It is a surprising fact to know that the prevalence of malnutrition in India is double that of subSaharan country. ${ }^{[1]}$ It has been 45 years since the launch of the Integrated Child Development Scheme (ICDS) and we still have $35.8 \%$ of undernourished children in our country makes one think about the drawbacks in our current approach. ${ }^{[2]}$

There are a wide variety of reasons for decreased weight inchildren under the age of 5 . Interestingly inadequate food security is considered as one of the primary reasons, however, it does not justify the $20.1 \%$ of underweight children belonging to high socioeconomic status. ${ }^{[2]}$ Other reasons include infections i.e. diarrhea and acute respiratory infections in children and it could be attributed to a moderate rate (approximately 62\%) of immunization in the under 5 age group. ${ }^{[2]}$

Additionally, the low weight of adolescent girls which leads to an intergenerational cycle of low birth weight and lack of knowledge of women regarding normal weight during infancy and pregnancy only adds to the problem. Moreover, only $43.3 \%$ of regular growth monitoring under ICDS makes us realize that we are losing a great opportunity of sensitizing mothers about normal growth in children when they are visiting Anganwadis. ${ }^{[2]}$ Owing to all these issues, there is a high prevalence of maternal and child anemia in our country. The standard solution of providing $20 \mathrm{mg}$ of elemental iron to children from 6 months to 6 years ${ }^{[3]}$ where the child's weight varies between $6 \mathrm{~kg}$ to $20 \mathrm{~kg}$ does not lead to desirable results in a practical setting. Overall, such ground realities make us wonder that are we only working on making the programmefeasible without thinking about the scientific data behind them. Hence, the formulationof a comprehensive child health programme in India is the need of the hour to not only treat but also prevent malnutrition.

To treat/prevent malnutrition, it is important to understand the normal growth of a child. WHO weight for age growth chart depicts that an average healthy weight newborn, say $2.8 \mathrm{~kg}$ at birth, gains nearly 900 gmof weight in the first month and $3.6 \mathrm{~kg}$ of weight in the next 3 months. Hence, according to the growth chart by $\mathrm{WHO}$ a normal weighing child should be around $7 \mathrm{kgat}$ four-month of age and $10 \mathrm{~kg}$ at 1 year of life. ${ }^{[4]}$ Beyond the age of 1 year, the child only gains $2 \mathrm{~kg}$ per year $(12 \mathrm{~kg}$ at $2 y e a r s, 14 \mathrm{~kg}$ at 3 years, $16 \mathrm{~kg}$ at 4 years, and $18 \mathrm{~kg}$ by 5 years of age). This indicates that a child has maximum growth potential in his/her 1 st year of life i.e. the 1 st 365 days of a child after birth and the 9 months of the antenatal period which equates to the first 635 days of child growth. After this crucial period, it is almost a plateau in terms of weight gain as the child has to gain only $2 \mathrm{~kg}$ per year.

CORRESPONDING AUTHOR:Dr Harivansh Chopra, National President Elect (2021-2022), Indian Association of Preventive \& Social Medicine, Former Professor \& Head, Department of Community Medicine, LLRM Medical College, Meerut

E Mail ID: harichop@gmail.com

ARTICLE CYCLE: Received: 05/06/2021; Revised: 12/06/2021; Accepted: 18/06/2021; Published:30/06/2021

CITATION: Chopra H. 1000 Versus 635 Days Approach for Prevention of Undernutrition in Children.J Comp Health.

2021;9(1):01-02. 
A similar pattern is seen with the height gain of the infant. A child is only $50 \mathrm{~cm}$ tall at birth while $75 \mathrm{~cm}$ at 1 year and $87 \mathrm{~cm}$ by age of 2 years. This equates to a gain of $25 \mathrm{~cm}$ after birth while only $12 \mathrm{~cm}$ in the next year. Moreover, the velocity of gain of height decreases as the age of the child increases. Also, at birth, the head circumference of the infant is $34 \mathrm{~cm}, 47 \mathrm{~cm}$ at 1 year of age, and $49 \mathrm{~cm}$ at the age of 2 years. All these patterns of gain of weight, height and increase in head circumference suggest the importance of the first 635 days of life of the child.

The argument here is, if a child who has not achieved normal weight, normal height, and normal head circumference by 1 year of age already lags behind his/her growth potential. Such a child, for example, could weigh $7 \mathrm{~kg}$ at the age of 1 , has to now gain $5 \mathrm{~kg}$ in next 1 year to fall into a normal category when his/her potential is only of $2 \mathrm{~kg}$ per year.

Thus, to promote child survival in a big country like India we should focus our programs to prevent malnutrition by taking action in the critical phase of maximum growth. Therefore, it is important to focus on the growth of the child during the maximum potential period (first 635 days) so that low birth weight can be prevented and the child attains the desired growth by the end of the first year to avoid any malnutrition scenario.

Moreover, if we shift our focus from 1st 1000 days to 1 st 635 days, it will tremendously reduce the load from the shoulders of our Anganwadi workers and they will be able to focus better on the growth phase that is so crucial.

To win this big fight I have come up with an approach i.e. BIG-WIN which is an acronym for:
1. B: exclusive breastfeeding for 6 months

2. I: infection prevention/treatment \& immunization

3. G: growth promotion/monitoring

4. W: appropriate weaning practice (complimentary feeding)\& safe water,washing hands

5. I: iron supplementation

6. $\mathbf{N}$ : nutrition education \& extra nutrition during pregnancy, lactation, and illness of the child Hence, a shift in strategy is the need of the hour. An infant should be the focus of attention as a mother would neither want to deliver a low birth weight child nor she would like her child to be malnourished. In a country like India where approximately 2.5 crore births are occurring annually, shifting the focus from under 2 years of age to under one year will not only reduce the burden of work of service providers but will also help in prevention of undernutrition in children.

\section{REFERENCES}

1. Sahu S., Kumar S., Bhat B., Premrajan K, Sarkar S, Roy $\mathrm{G}$, et al. Malnutrition among under 5 children in India and strategies for control: J Nat Biol Med 2015;6:18-23. Last accessed on 10.06.2021.

2. GOI, Ministry of Health \& Family Welfare. National Family Health Survey -4 (2015-16) available at http://rchiips.org/nfhs/pdf/NFHS4/India.pdf accessed on $30 / 05 / 2021$

3. Anemia Mukt Bharat available at https://anemiamuktbharat.info/home/interventions/ accessed on 30/05/21

4. WHO Growth Charts - available at https://www.cdc.gov/growthcharts/who_charts.htm\#: : text=The $\% 20 \mathrm{WHO} \% 20$ growth\%20charts\%20are,data $\% 20$ measured\%20at\%20frequent\%20intervals. accessed on 30/05/2021

5. First Thousand Days - National Health Missionavailable at https://nhm.gov.in/images/pdf/programmes/RBSK/Re source_Documents/Journey_of_The_First_1000_Day s.pdf accessed on 30/05/2021 